\title{
SEROTONIN INVOLVEMENT IN DESCENDING INHIBITION OF SPINAL NOCICEPTIVE TRANSMISSION PRODUCED BY STIMULATION OF MEDIAL DIENCEPHALON AND BASAL FOREBRAIN $^{1}$
}

\author{
E. CARSTENS, ${ }^{2}$ J. D. MACKINNON, AND M. J. GUINAN \\ Department of Animal Physiology, University of California, Davis, Davis, California 95616
}

Received June 22, 1982; Revised April 7, 1983; Accepted May 5, 1983

\begin{abstract}
The responses of single lumbar dorsal horn neurons to noxious radiant heat stimuli $\left(50^{\circ} \mathrm{C}, 10\right.$ sec) applied to glabrous footpad skin were recorded in cats anesthetized with sodium pentobarbital and $70 \% \mathrm{~N}_{2} \mathrm{O}$. Responses were markedly reduced during electrical stimulation (100-msec trains at $100 \mathrm{~Hz}, 3 / \mathrm{sec}$, up to $400 \mu \mathrm{A}$ ) at sites in the medial diencephalic periventricular gray (PVG), preoptic area, and basal forebrain. A role for serotonin (5-hydroxytryptamine, 5-HT) was investigated by determining whether descending inhibition from these areas could be affected by (1) acute systemic administration of the 5-HT antagonist methysergide, or (2) depletion of central 5-HT levels by pretreatment with the 5 -HT synthesis inhibitor $p$-chlorophenylalanine (PCPA; $500 \mathrm{mg} / \mathrm{kg}$, i.p.). Inhibition produced by stimulation at these sites was reduced or abolished in 22 cases following administration of methysergide $(0.2$ to $1 \mathrm{mg} / \mathrm{kg})$ to non-pretreated cats. In the PCPA-pretreated cats, stimulation in preoptic or basal forebrain arcas inhibited the responses of 26 units to noxious skin heating to varying degrees; PVG stimulation inhibited the responses of 14 of 26 units, while the remainder were unaffected. The mean current threshold for inhibition produced by PVG or preoptic/basal forebrain stimulation was significantly higher, while mean inhibition at $200 \mu \mathrm{A}$ was significantly lower, in units from PCPA-pretreated cats compared to those from non-pretreated cats. The results indicate that 5-HT may be involved in the mediation of spinal inhibition produced by medial diencephalic and basal forebrain stimulation.
\end{abstract}

Neurons in the spinal dorsal horn are known to be under descending inhibitory influences (Fields and Basbaum, 1978; Willis, 1982). Many dorsal horn neurons in laminae I and IV to VI respond differentially to noxious peripheral stimuli and are thought to participate in the central transmission of nociceptive information (Price and Dubner, 1977). Such neurons are inhibited by electrical stimulation in medial brainstem sites extending from the medullary raphe nuclei through the midbrain periaqueductal gray (PAG) into the medial diencephalic periventricular gray (PVG), preoptic area, and posterior basal forebrain (Oliveras et al., 1974; Fields et al., 1977; Guilbaud et al., 1977; Willis et al., 1977; Belcher et al., 1978; Carstens et al., 1979, 1982; Rivot et al., 1980; Carstens, 1982). Electrical stimulation at similar brain-

\footnotetext{
${ }^{1}$ We are grateful for the generous gift of methysergide from Sandez, Inc. We wish to thank P. Buchignani for typing the manuscript and Prof. M. Zimmermann for his very helpful comments and criticism of the work.

${ }^{2}$ To whom correspondence should be addressed.
}

stem sites, including the medullary nucleus raphe magnus (NRM; Oliveras et al., 1975), midbrain PAG (Mayer and Leibeskind, 1974; Oliveras et al., 1974), medial diencephalon (Schmidek et al., 1971; Black et al., 1972; Hosobuchi et al., 1977; Rhodes, 1979; Oleson et al., 1980), and medial basal forebrain (Heath and Mickle, 1960; Gol, 1967; Breglio et al., 1970; Mayer and Liebeskind, 1974; Abbot and Melzack, 1978), has been reported to suppress nocifensive responses and human chronic pain. It has been suggested that this so-called stimulationproduced analgesia may be partly mediated via descending inhibition of spinal neurons transmitting nociceptive information (Mayer and Price, 1976).

Considerable evidence supports a role for serotonin (5hydroxytryptamine, $5-\mathrm{HT}$ ) in the mediation of analgesia and descending spinal inhibition produced by medullary NRM and midbrain PAG stimulation (Messing and Lytle, 1977; Willis, 1982). In particular, depletion of central 5 -HT levels with the 5-HT synthesis inhibitor $p$-chlorophenylalanine (PCPA), as well as acute blockade of central 5-H'T receptors with antagonists such as meth- 
ysergide, reduced or abolished the analgesic (Akil and Liebeskind, 1975; Hayes et al., 1977; Satoh et al., 1980) and inhibitory spinal effect (Rivot et al., 1980; Carstens et al., 1981; Yezierski et al., 1982) produced by PAG or NRM stimulation. However, little is known concerning the neurotransmitter(s) that mediate(s) descending inhibition and analgesia produced by medial diencephalic and basal forebrain stimulation. Since these latter areas have anatomical connections with midbrain PAG and/ or medullary NRM (see "Discussion" for references), it is possible that spinal inhibition produced by diencephalic or forebrain stimulation is mediated via activation of neurons in the PAG and/or NRM, which in turn give rise to inhibitory spinal projections. It would then be expected that the effects of medial diencephalic and basal forebrain stimulation would be mediated at least partly by $5-\mathrm{HT}$. We have therefore investigated this possibility by determining whether this inhibition is affected by PCPA or the 5-HT antagonist methysergide. An abstract of this work has appeared (Guinan et al., 1982).

\section{Materials and Methods}

Electrophysiological experiments were performed using 17 untreated female cats $(2.2$ to $3.3 \mathrm{~kg})$ and 5 female cats (2.5 to $3.3 \mathrm{~kg}$ ) pretreated with PCPA (Sigma Chemical Co., suspended in sesame oil; $500 \mathrm{mg} / \mathrm{kg}$, i.p.) $72 \mathrm{hr}$ before the experiment.

The procedures for surgery, stimulation and recording, and histology were identical to those described previously (Carstens, 1982). Briefly, the animals were anesthetized with sodium pentobarbital (Nembutal; $40 \mathrm{mg} / \mathrm{kg}$, i.p.) and artificially ventilated with a gaseous mixture of $\mathrm{N}_{2} \mathrm{O}$ and $\mathrm{O}_{2}(12: 1)$ following paralysis. The lumbosacral spinal cord was exposed by laminectomy, and tungsten microelectrodes ( 12 megohms) were used to record the responses of single dorsal horn units to noxious radiant heating of glabrous footpad skin. Step increases from an adapting temperature of $30^{\circ} \mathrm{C}$ to the desired end temperature $(42$ to $52^{\circ} \mathrm{C}$ ) lasting $10 \mathrm{sec}$ were produced at 3 -min intervals using a feedback-controlled lamp focused on the skin (Beck et al., 1974). A digital computer was used to construct poststimulus time histograms (PSTHs) of unit responses, which were quantified as the total number of impulses during the 10 -sec period starting $5 \mathrm{sec}$ after the onset of heating. Brain stimulation (100-msec trains of 0.1 -msec pulses at $100 \mathrm{~Hz}, 3 / \mathrm{sec}$, amplitude 25 to 400 $\mu \mathrm{A})$ was applied via separate concentric bipolar steel electrodes, one of which was stereotaxically lowered into the PVG region (stereotaxic coordinates: anterior, +8 to +12 ; ventral, +2 to -2 , near the midline; Bleier, 1961 ; Snider and Niemer, 1961) and the other into the medial preoptic area or basal forebrain (anterior, +14 to +16 ; ventral, +2 to -6 , near the midline; Andy and Stephan, 1964). Unit heat-evoked responses without brain stimulation (controls), and again during brain stimulation at each site, were recorded successively. Brain stimulation was begun $10 \mathrm{sec}$ before the onset of heating and lasted $25 \mathrm{sec}$. The brain stimulation electrodes were left at each position for the duration of the experiment. The effect of PVG, preoptic, or basal forebrain stimulation on a unit heat-evoked response was expressed as a percentage of the control response.
In the PCPA-pretreated cats, the effects of PVG, preoptic, or basal forebrain stimulation at various current intensities on unit $50^{\circ} \mathrm{C}$ heat-evoked responses, as well as effects of stimulation at one intensity on unit responses to graded noxious heat stimuli, were determined. In the non-pretreated cats the effect of acute systemic administration of methysergide (Sandoz, Inc.; 0.2 to $1 \mathrm{mg} / \mathrm{kg}$, i.v.; duration of injection $\leq 2 \mathrm{~min}$ ) was determined by comparing the magnitude of inhibition produced by brain stimulation of a constant intensity (range: 50 to $300 \mu \mathrm{A}$ ) before and after the drug injection.

Electrolytic lesions made at the stimulation and recording sites were reconstructed histologically in cresyl violet-stained $40-\mu \mathrm{m}$ frozen sections.

\section{Results}

Recording and stimulation sites. All units selected gave reproducible high frequency responses to repeated $(1 / 3$ min) $50^{\circ} \mathrm{C}$ heat stimuli. Thirteen of the 17 units studied in the non-pretreated cats receiving acute methysergide were of the class 2 (Handwerker et al., 1975) or wide dynamic range (Price and Dubner, 1977) type, responding to hair movement $(N=10)$ or pressure $(N=3)$ as well as to pinch and noxious heat. Two responded only to noxious pinch and heat (class 3 or nociceptive specific types; Price and Dubner, 1977), and two were not adequately tested with mechanical stimuli. Cutaneous receptive fields spanned one to two toes $(N=6)$ or larger areas $(N=9)$. Units with high mechanical thresholds tended to have smaller receptive fields. Histologically localized recording sites were in laminae IV to VI (Fig. $1 A$, open circles).

In the five cats pretreated with PCPA, 34 units responded to noxious skin heating. However, eight were discarded since they did not respond to subsequent heat stimuli. Similar "habituating" units were reported previously in PCPA-pretreated cats (Carstens et al., 1981). Each of the 26 units giving reproducible responses to heat was of the class 2 or wide dynamic range type, responding at lowest threshold to hair movement $(N=$ $17)$, touch $(N=2)$, or pressure $(N=5)$; two were inadequately tested with mechanical stimuli. There were equal numbers of units with small (one to two toes) and larger receptive fields. Unit recording sites were located in laminae IV to VI (Fig. 1A, solid circles).

PVG (Fig. $1 B$, circles) and medial preoptic or basal forebrain (Fig. $1 B$, triangles) stimulation sites are compiled in Figure $1 B$. Stimulation at each site in nonpretreated cats (Fig. 1B, open symbols) markedly reduced the responses of each unit tested. Stimulation at sites in PCPA-pretreated cats (Fig. 1B, solid symbols) was less effective, as detailed below.

Methysergide. In the non-pretreated cats, PVG or preoptic/basal forebrain stimulation consistently inhibited responses of dorsal horn units to $50^{\circ} \mathrm{C}$ heat stimuli as previously reported (Carstens, 1982; Carstens et al., 1982). This is illustrated in Figure 2, showing the response of a dorsal horn unit to the heat stimulus without brain stimulation (upper left PSTHs in Fig. 2, $A$ and $B$ ) and reduction of the response during medial preoptic or PVG stimulation (lower left PSTHs in Fig. 2, $A$ and $B$, respectively). Following administration of methysergide 

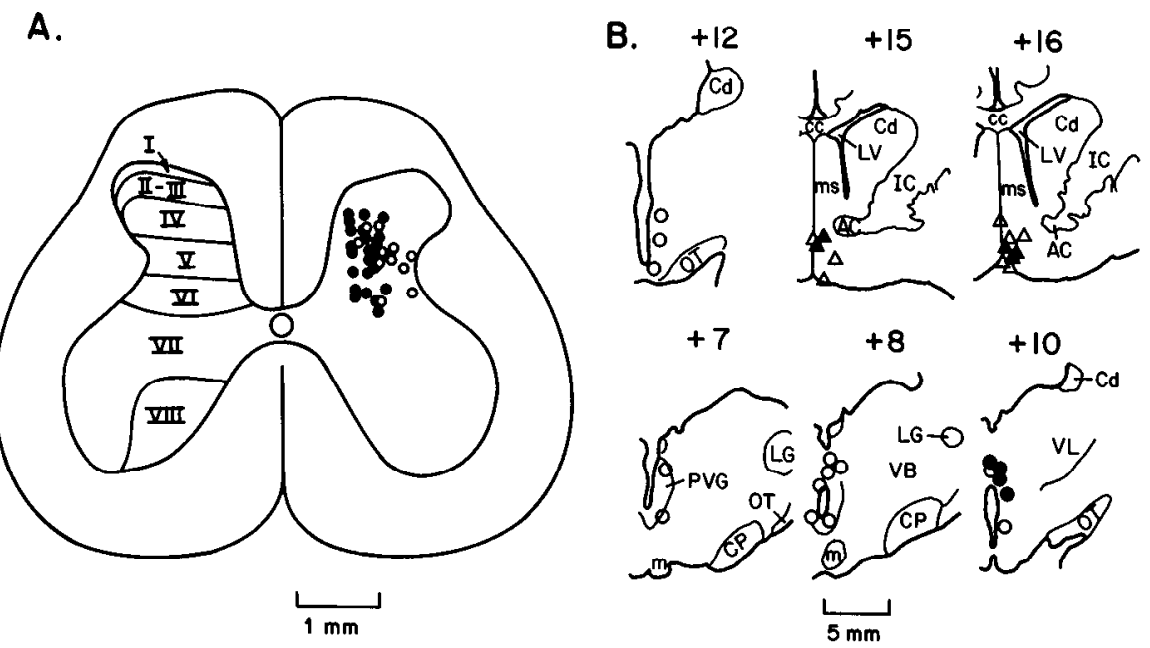

Figure 1. Recording and stimulation sites. $A$, Spinal recording sites for units from PCPA-pretreated cats $(O)$ and from non-pretreated cats $(O)$, compiled on a representative section through the spinal cord at $\mathrm{L}_{6}$. The lamination scheme of Rexed (1952) is shown to the left. B, Stimulation sites in PCPA-pretreated (solid symbols) and non-pretreated cats (open symbols), compiled on representative frontal sections at the indicated anterior levels. Triangles denote medial preoptic or basal forebrain sites; circles denote PVG sites. The right side is ipsilateral to spinal recording sites. Abbreviations for this and subsequent figures: $A C$, anterior commissure; $c c$, corpus callosum; $C d$, caudate nucleus; $C P$, cerebral peduncle; $F$, fornix; $I C$, internal capsule; $L G, L G N$, lateral geniculate nucleus; $L V$, lateral ventricle; $m$, mammillary body; $m s$, medial septal nucleus; $M T$, mamillothalamic tract; $O T$, optic tract; $P V G$, periventricular gray; $V B$, ventrobasal thalamic nuclei; $V L$, ventral lateral nucleus.

$(0.2 \mathrm{mg} / \mathrm{kg}$, i.v. $)$, the unit's control responses were near the predrug level (upper middle PSTHs, Fig. 2, $A$ and $B)$. However, responses were suppressed less during preoptic or PVG stimulation (lower middle PSTHs in Fig. 2, $A$ and $B$ ). Inhibition recovered within $75 \mathrm{~min}$ (lower right PSTHs in Fig. 2, $A$ and $B$ ). Note that the rebound in unit firing following termination of PVG stimulation increased following methysergide (lower PSTHs in Fig $2 B$ ), an effect observed in a few other units. In Figure $3 A$, inhibition of another unit's response by PVG stimulation was abolished following methysergide, with recovery within $29 \mathrm{~min}$.

Figure $3 B$ summarizes the effect of methysergide to reduce or abolish inhibition produced by PVG (Fig. $3 B$, circles) or preoptic/basal forebrain stimulation (Fig. $3 B$, triangles). The degree of inhibition produced by brain stimulation (heat-evoked response during brain stimulation expressed as a percentage of the preceding control) prior to methysergide is plotted against inhibition within 20 min after methysergide for each unit. With both low (Fig. 3B, open symbols) and high doses (Fig. 3B, solid symbols) of methysergide, points lie above the diagonal, indicating that inhibition was reduced or abolished in all cases. The maximal reduction of inhibition was evident within 10 to 30 min following methysergide, and inhibition recovered within 75 min in 10 units but did not recover after more than $60 \mathrm{~min}$ in 3 units. In two units from PCPA-pretreated cats, PVG and basal forebrain stimulation inhibited heat-evoked responses, and this inhibition was abolished following methysergide in both cases.
Injection of equal volumes of $0.9 \%$ saline had no effect on inhibition. Injection of 0.5 to $1 \mathrm{mg} / \mathrm{kg}$ of naloxone in some of these experiments also had no effect on inhibition (unpublished observations). In several cases, inhibition was abolished following methysergide in the absence of blood pressure changes, although reductions in blood pressure (10 to $30 \mathrm{~mm} \mathrm{Hg}$ ) were often observed especially following $1 \mathrm{mg} / \mathrm{kg}$ of methysergide.

PCPA. Of the 26 units tested in PCPA-pretreated cats, the heat-evoked responses of each were inhibited by preoptic or basal forebrain stimulation. PVG stimulation did not inhibit the responses of 12 of the 26 units, whereas the remainder were inhibited to varying degrees.

The relationship between brain stimulation intensity and degree of inhibition was investigated in 14 units with PVG stimulation and in 15 units with preoptic or basal forebrain stimulation (Fig. 4). Figure $4 A$ shows the responses of a dorsal horn unit to $50^{\circ} \mathrm{C}$ heat stimuli without (upper row of PSTHs in Fig. 4A) and during PVG stimulation (lower row of PSTHs in Fig. $4 A$ ) at the indicated current intensities. The same unit's responses (expressed as percentage of control) are plotted against PVG stimulation intensity in Figure $4 B$, showing that inhibition increased with stimulation intensity, with a threshold for inhibition near $200 \mu \mathrm{A}$. Similar plots are compiled for 14 units with PVG stimulation in Figure $4 C$ and for 15 units with preoptic or basal forebrain stimulation in Figure $4 D$. Linear regression analysis was performed to calculate the threshold ( $100 \%$ of control) and the slope of the current-inhibition plot (termed the recruitment index; Carstens et al., 1980). Mean thresholds 
A.

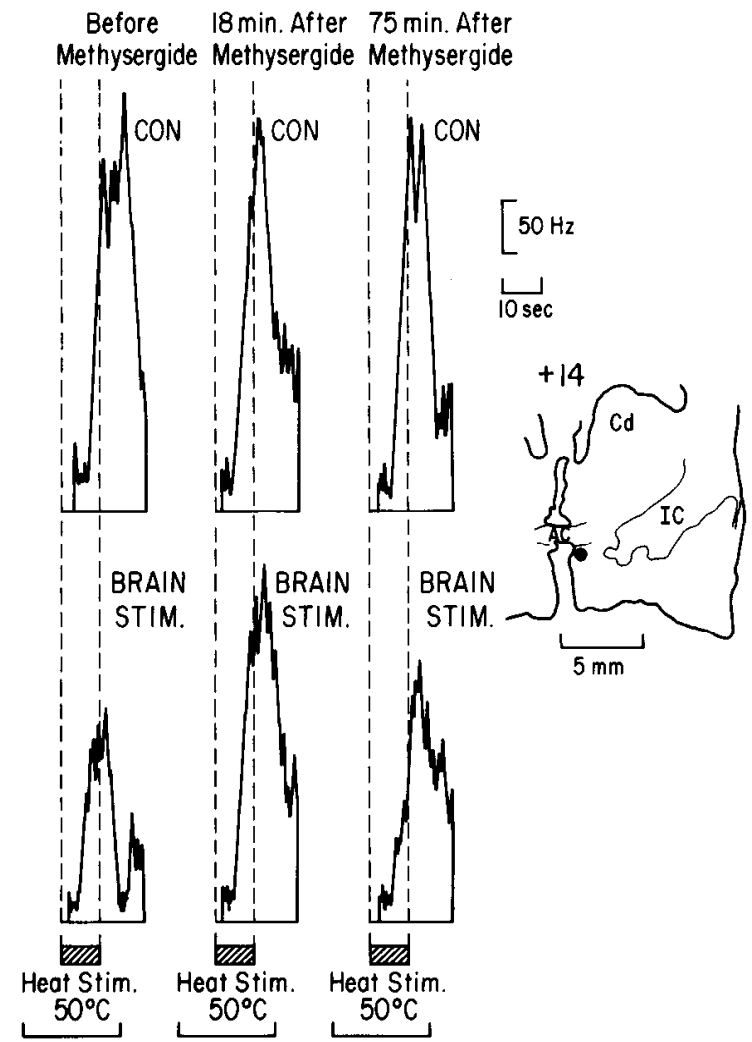

B.

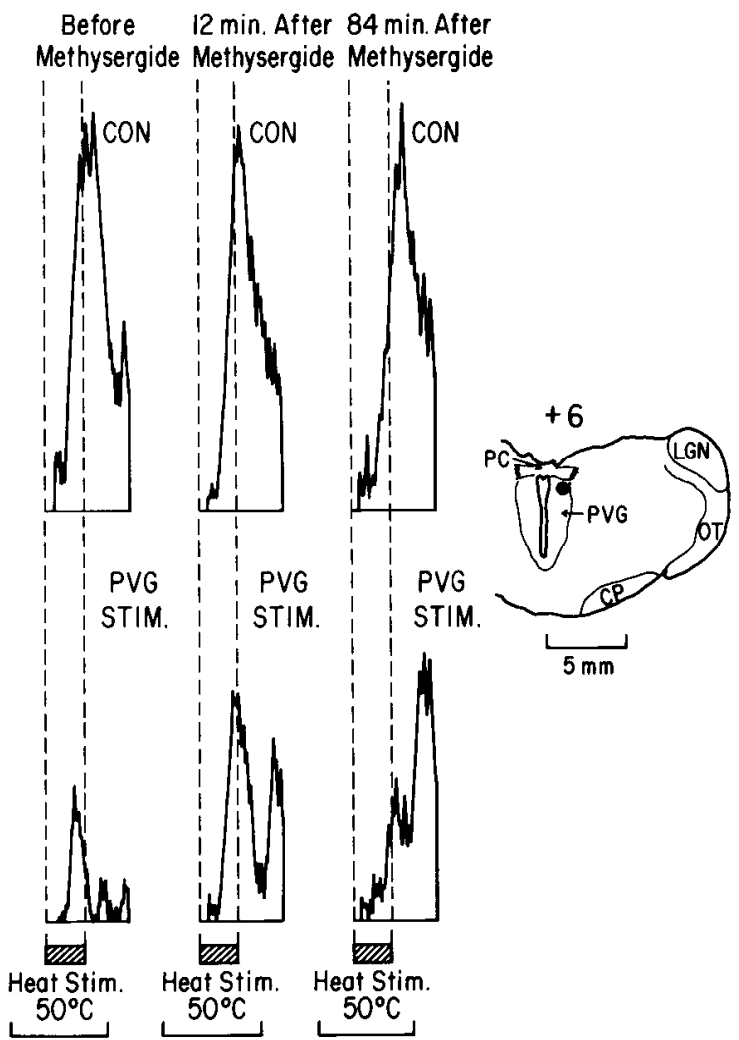

Figure 2. Reduction by methysergide of descending inhibition produced by medial preoptic or PVG stimulation. A, PS'IHs (bin width, $0.4 \mathrm{sec}$ ) of a dorsal horn unit's responses to $50^{\circ} \mathrm{C}$ heat stimuli (striped bars) applied to footpad skin, without (CON, upper row) and during $300 \mu \mathrm{A}$ stimulation (lower row) at the medial preoptic site shown in the drawing to the right. Nonpretreated cat. Duration of brain stimulation $(25 \mathrm{sec})$ is indicated by the brackets below. Time relative to methysergide administration applies to the lower PSTH in each column. Note that the unit's response was reduced during preoptic stimulation before methysergide (lower left PSTH), but that the response during identical preoptic stimulation was near the control level 18 min after administration of methysergide $(0.5 \mathrm{mg} / \mathrm{kg}$, i.v.) (lower middle PSTH). Inhibition partially recovered within 75 min (lower right PSTH). $B$, PSTHs of responses of the same unit in $A$ to $50^{\circ} \mathrm{C}$ heat stimuli, without (CON, upper rou) and during PVG stimulation (lower row) at the site shown to the right. Format as in $A$. Note the rebound in unit firing following termination of PVG stimulation (lower middle PSTH) which increased with time (lower right PSTH) after methysergide. Abbreviations are as in Figure $1 B$.

and recruitment indices for PVG or preoptic/basal forebrain stimulation are given in Table I. With both PVG and preoptic/basal forebrain stimulation, mean thresholds were significantly higher, and the recruitment indices were significantly lower, in the PCPA-pretreated cats compared to non-pretreated (control) cats (control data from Carstens, 1982; Carstens et al., 1982). In addition, mean inhibition of unit responses to $50^{\circ} \mathrm{C}$ heat stimuli produced by $\mathrm{PVG}$ or preoptic/basal forebrain stimulation at $200 \mu \mathrm{A}$ was significantly less in PCPApretreated compared to control groups (Table I).

The effect of PVG or preoptic/basal forebrain stimulation on intensity coding by dorsal horn units of graded noxious heat stimuli was also tested in units from PCPApretreated cats (Fig. 5). Figure $5 A$ shows a unil's graded responses to heat stimuli at the indicated temperatures, without (CON; left column of PSTHs in Fig. $5 A)$ and during PVG stimulation (right column in Fig. $5 A$ ). This unit's integrated responses with (Fig. $5 B$, open circles) and without (control; Fig. 5B, solid circles) PVG stimulation are plotted against skin stimulus temperature in
Figure 5B. During PVG stimulation, the slope of the linear temperature-response function was reduced (to $63 \%$ of control) with a $2.3^{\circ} \mathrm{C}$ increase in the extrapolated firing threshold. Figure $5 \mathrm{C}$ similarly plots the mean responses of 11 units without (control; solid circles, Fig. 5C) and with (open circles, Fig. 5C) PVG or preoptic/ basal forebrain stimulation $(100$ to $300 \mu \mathrm{A})$. The mean slope reduction produced by brain stimulation was to $67 \%$ of control, and the mean threshold was increased by $1.9^{\circ} \mathrm{C}$.

\section{Discussion}

Inhibition of spinal dorsal horn neuronal responses to noxious skin heating produced by stimulation of PVG, medial preoptic area, and posterior basal forebrain was reduced or abolished following systemic administration of the 5-HT antagonist, methysergide, and was significantly weaker in animals whose central 5 -HT levels had been depleted by pretreatment with PCPA. These results indicate that 5-HT may play a role in mediating descend- 


\section{A. Before $8 \mathrm{~min}$. After $29 \mathrm{~min}$. After
Methysergide Methysergide Methysergide}

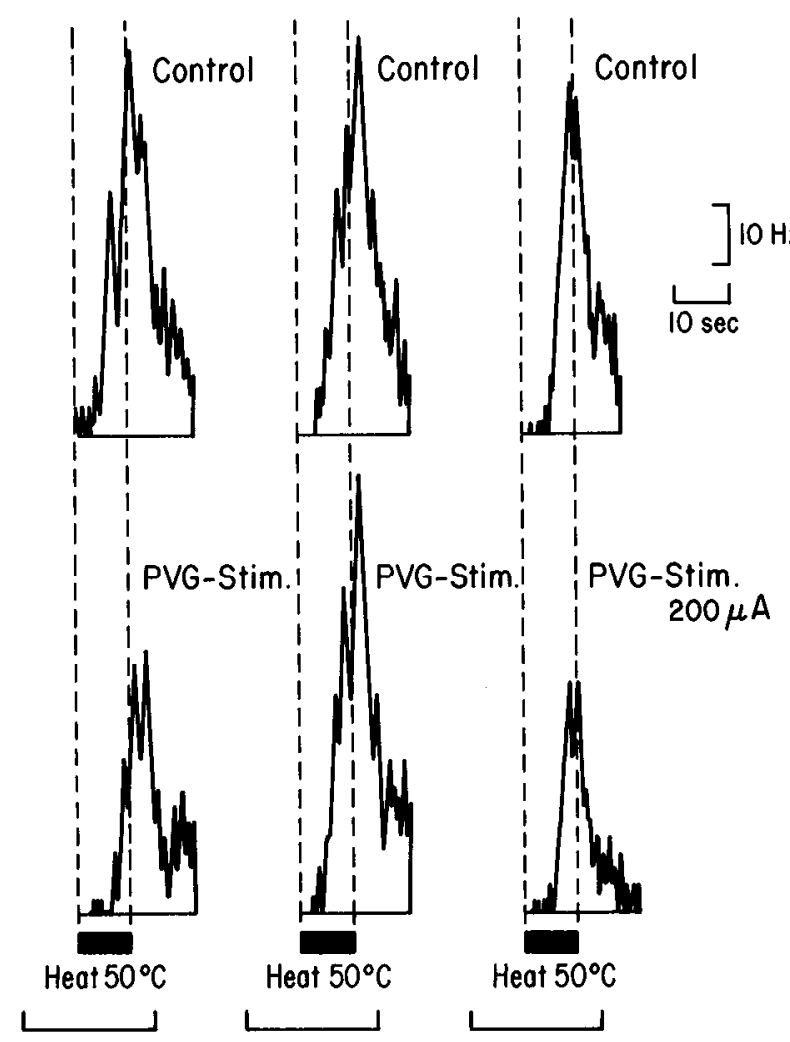

B.
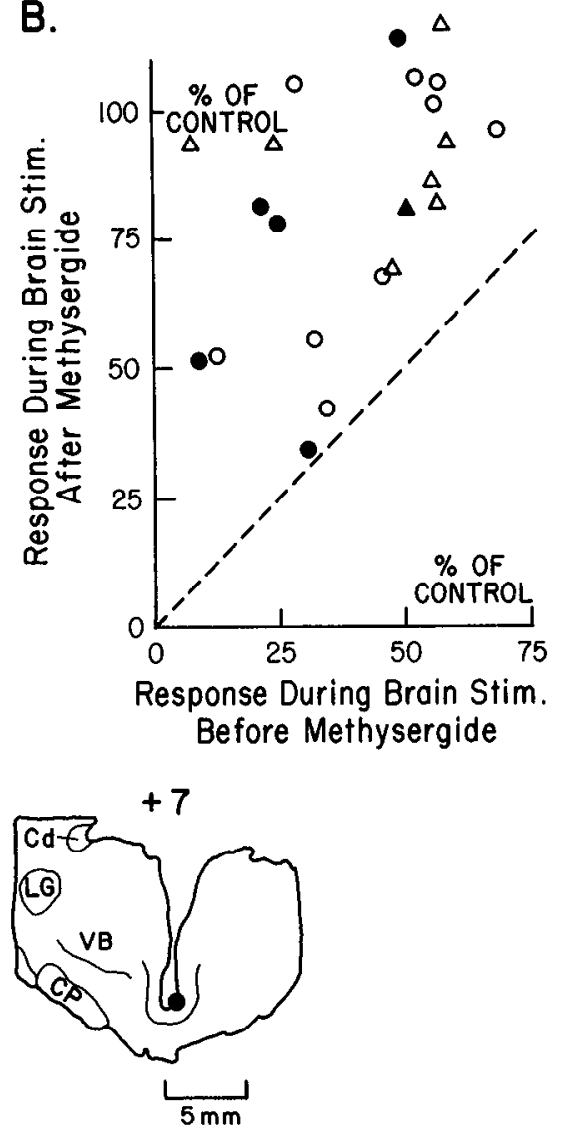

Figure 3. Reduction or blockade of descending inhibition by methysergide. $A$, PSTHs of another unit's responses to $50^{\circ} \mathrm{C}$ heat stimuli, without (Control, upper row) and during (lower row) PVG stimulation at the site shown to the right. Format as in Figure 2. $B$, The graph plots $50^{\circ} \mathrm{C}$ heat-evoked response of each dorsal horn unit during brain stimulation (expressed as percentage of control response in the absence of brain stimulation) before methysergide (abscissa) against response of the same unit during brain stimulation within 20 min after administration of methysergide (ordinate). Each point represents a separate unit. The dashed diagonal line indicates equal inhibition before and after methysergide. $\Delta, \Delta$ : medial preoptic or basal forebrain stimulation; , O: PVG stimulation. Open symbols, low dose of methysergide $(0.2$ to $0.5 \mathrm{mg} / \mathrm{kg}) ;$ solid symbols, $1 \mathrm{mg} / \mathrm{kg}$ dose of methysergide. Abbreviations are as in Figure $1 B$.

ing inhibition from these areas, within the limitations of the specificity of the drug treatments as discussed below.

Methysergide. There is considerable evidence that the peripheral 5-HT antagonist methysergide also acts centrally. Systemic administration of methysergide and other putative 5-HT antagonists (metergoline, cinanserin, cyproheptadine) blocked inhibition produced by midbrain PAG stimulation of spinal neuronal responses to noxious skin input (Carstens et al., 1981; Yezierski et al., 1982), blocked bulbospinal inhibition of monosynaptic reflexes (Clineschmidt and Anderson, 1970; but see Sinclair and Sastry, 1974), blocked dorsal root potentials evoked by medullary NRM stimulation (Proudfit et al., 1980), and blocked analgesia produced by stimulation in or opiate microinjection into the midbrain PAG or medullary NRM (Yaksh et al., 1976; Hayes et al., 1977; Satoh et al., 1980).

Methysergide presently reduced or abolished descending inhibition produced by medial diencephalic and basal forebrain stimulation. This cannot be ascribed to a general systemic effect such as hypotension, since methysergide frequently blocked inhibition in the absence of blood pressure changes. That methysergide did not uniformly abolish inhibition may have been due to coacti- vation of a nonserotonergic inhibitory system (see below). Blockade of inhibition occurred within $20 \mathrm{~min}$, and inhibition recovered within $75 \mathrm{~min}$ in many, but not all, units. Inhibition of spinothalamic neurons produced by PAG stimulation only partially recovered following its blockade by larger doses of methysergide (2 to $5 \mathrm{mg} /$ kg)(Yezierski et al., 1982).

The site of action of methysergide cannot be determined from experiments using the systemic route of administration. One possible site is in the spinal dorsal horn, in which are located 5-HT-containing synaptic terminals originating from neurons in NRM (Ruda and Gobel, 1980). 5-HT has a depressant action on dorsal horn neurons (Randić and Yu, 1976; Belcher et al., 1978; Headley et al., 1978). Methysergide antagonized the depressant action on dorsal horn neurons of 5-H'T, but not noradrenaline, administered into the substantia gelatinosa (Griersmith and Duggan, 1980), suggesting possible specificity of methysergide for 5-HT receptors. 5-HT antagonists most effectively blocked bulbospinal reflex inhibition when injected into the arterial supply of the spinal cord (Clineschmidt and Anderson, 1970). On the other hand, methysergide failed to reduce inhibition of spinal dorsal horn neurons produced by NRM stimula- 
A. UNIT 10278I-3

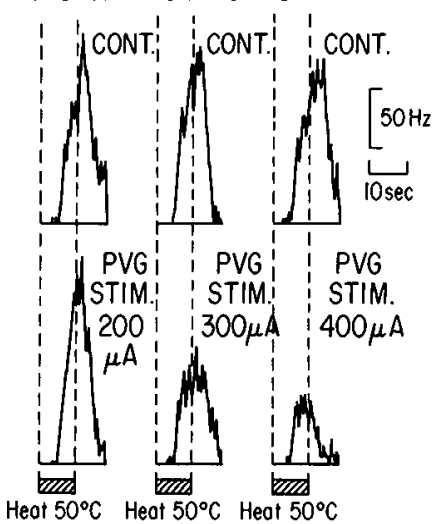

C. 14 UNITS

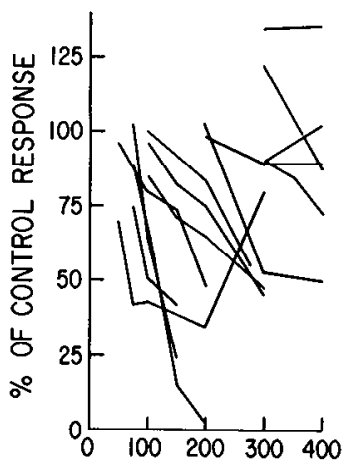

PVG STIM. INTENSITY $(\mu \mathrm{A})$
B. UNIT 102781-3

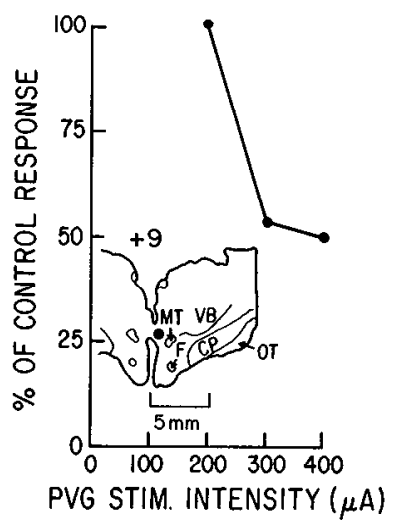

D. 15 UNITS

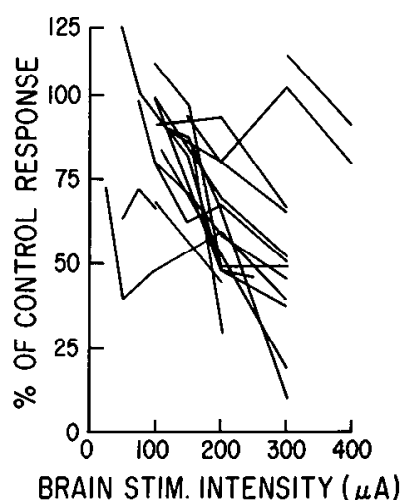

Figure 4. Recruitment of descending inhibition by graded increases in brain stimulation intensity in PCPA-pretreated cats. $A$, PSTHs (bin width, $0.4 \mathrm{msec}$ ) of dorsal horn unit's responses to repeated $50^{\circ} \mathrm{C}$ heat stimuli (bars below), without (CONT., upper row) and during concomitant PVG stimulation (lower row) at the indicated current intensities. From a PCPApretreated cat. Brain stimulation began $10 \mathrm{sec}$ before onset of the heat stimulus and lasted $25 \mathrm{sec} . B$, The graph plots magnitude of $50^{\circ} \mathrm{C}$ heat-evoked response (expressed as percentage of control) against intensity of PVG stimulation for the same unit shown in $A$. PVG stimulation site is shown in the inset (for abbreviations, see Fig. $1 B$ ). $C$, Graph as in $B$, plotting the responses of 14 units from PCPA-pretreated cats against PVG stimulation intensity. $D$, Graph as in $C$, plotting the responses of 15 units from PCPA-pretreated cats against intensity of medial preoptic or basal forebrain stimulation.

tion in the cat (Belcher et al., 1978; Griersmith et al., 1981) and only weakly reduced inhibition of primate spinothalamic neurons produced by NRM stimulation, in contrast to methysergide's strong blockade of inhibition produced by PAG stimulation (Yezierski et al., 1982). Instead of a spinal site of action, methysergide could disrupt a potential excitatory serotonergic projection to NRM from the dorsal raphe nucleus (Yezierski et al., 1981), although such a projection has not been found in the cat (Abols and Basbaum, 1981). It was recently reported that 5 -HT inhibits, rather than excites, raphe-spinal neurons in the monkey (Willcockson et al., 1982). The site of action of methysergide thus remains uncertain.

PCPA. PCPA selectively inhibits 5 -HT synthesis (Koe and Weissman, 1966) and, at doses comparable to those used presently $(500 \mathrm{mg} / \mathrm{kg}$ or two doses of $300 \mathrm{mg} / \mathrm{kg}$ ), reduced 5 -HT levels to $40 \%$ of control in the brainstem (Keller, 1972) and to 16 to $54 \%$ of control in the cat's thoracic spinal cord (Coote et al., 1978). We found descending inhibition from the medial diencephalon and basal forebrain to be weaker, but not absent, in PCPApretreated cats (Table I). Inhibition in PCPA-pretreated cats may have been mediated by residual $5-\mathrm{HT}$ and/or by coactivation of a nonserotonergic descending inhibitory system. That inhibition in PCPA-pretreated cats was blocked following administration of methysergide in two units might be interpreted as evidence favoring the former possibility. Alternatively, it was previously reported that stimulation in the lateral midbrain reticular formation (LRF) inhibited dorsal horn unit responses to noxious skin heating (Carstens et al., 1980) and that this inhibition was not reduced by PCPA (Carstens et al., 1981). LRF stimulation resulted in parallel rightward shifts in unit intensity coding functions for graded noxious heat stimuli with increases in the neuronal firing threshold, similar to the present effect of brain stimulation in PCPA-pretreated cats (Fig. 5). It is therefore possible that the higher stimulation intensities needed to produce inhibition in the PCPA-pretreated cats may have coactivated the nonserotonergic inhibitory LRF system. In this context, neurons in the PVG and medial preoptic area have been reported to project to the mid-

TABLE I

Comparison of quantitative parameters for inhibition produced by PVG and medial preoptic or basal forebrain stimulation in untreated control cats $^{a}$ and cats pretreated with PCPA

\begin{tabular}{|c|c|c|c|c|c|c|}
\hline & \multicolumn{3}{|c|}{ Control } & \multicolumn{3}{|c|}{ PCPA (500 mg/kg) } \\
\hline & Mean & SD & $\mathbf{N}$ & Mean & SD & $\mathbf{N}$ \\
\hline \multicolumn{7}{|l|}{ PVG Stimulation } \\
\hline Mean inhibition (\% control) at $200 \mu \mathrm{A}$ & 41.7 & 31.3 & 15 & $67.2^{b}$ & 37.1 & 14 \\
\hline Mean threshold $(\mu \mathrm{A})$ for inhibition & 67.4 & 67 & 14 & $144.9^{b}$ & 127.5 & 13 \\
\hline Recruitment index (\% inhibition $/ 100 \mu \mathrm{A}$ ) & 46 & 25 & 15 & $23.5^{b}$ & 30 & 14 \\
\hline Mean current $(\mu \mathrm{A})$ at $50 \%$ inhibition & 170.1 & 79.2 & 14 & $266.2^{b, c}$ & 130.8 & 13 \\
\hline \multicolumn{7}{|l|}{ Medial Preoptic/Basal Forebrain Stimulation } \\
\hline Mean inhibition ( $\%$ control) at $200 \mu \mathrm{A}$ & 31 & 21.7 & 14 & $62.9^{b}$ & 19.2 & 15 \\
\hline Mean threshold $(\mu \mathrm{A})$ for inhibition & 25.3 & 18.7 & 15 & $98.4^{b}$ & 26.5 & 15 \\
\hline Recruitment index (\% inhibition $/ 100 \mu \mathrm{A}$ ) & 41 & 28 & 14 & $25^{b}$ & 15 & 15 \\
\hline Mean current $(\mu \mathrm{A})$ at $50 \%$ inhibition & 126.1 & 52.9 & 13 & $233.9^{b, c}$ & 70.3 & 15 \\
\hline
\end{tabular}

a Data from Carstens, 1982, and Carstens et al., 1982.

${ }^{b}$ Significantly different from control $(p<0.05, t$ test).

${ }^{c}$ Values represent underestimates, since four units in each group were not inhibited at currents above the maximum used (400 $\mu \mathrm{A}$ ) for this calculation. 
A. UNIT $11281-2$

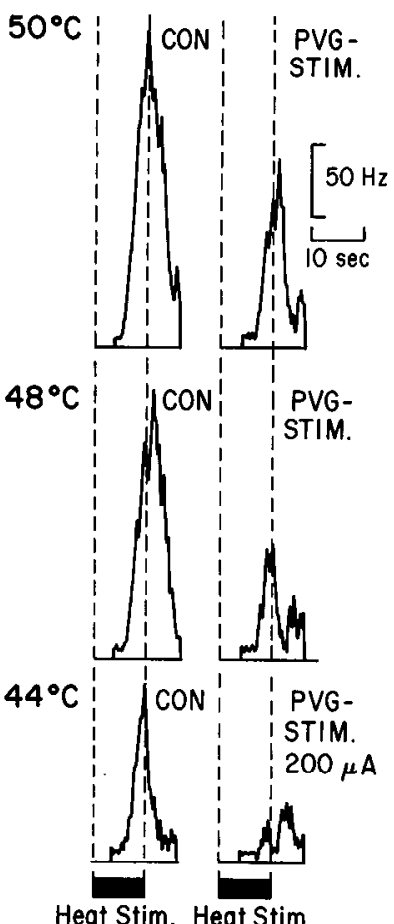

B. UNIT $|128|-2$

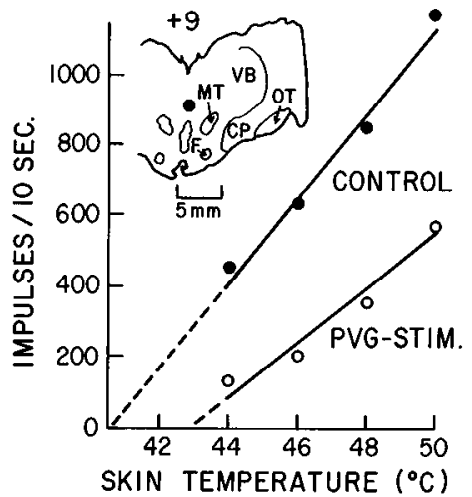

C. MEAN OF II UNITS

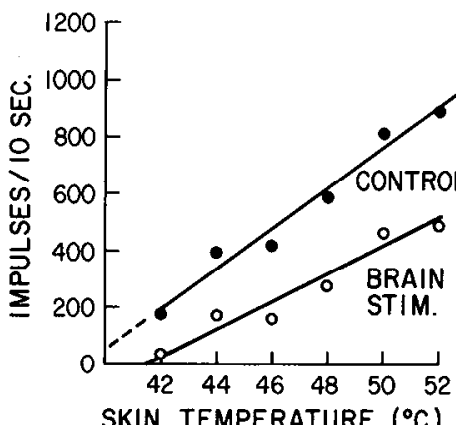

SKIN TEMPERATURE $\left({ }^{\circ} \mathrm{C}\right)$

Figure 5. Effect of PVG stimulation on intensity coding for graded noxious heat stimuli by dorsal horn units in PCPApretreated cats. $A$, PSTHs (bin width, $0.4 \mathrm{sec}$ ) of dorsal horn unit's response to heat stimuli at the indicated temperatures, without (CON, left column of PSTHs) and during concomitant PVG stimulation (right column). At each randomly selected temperature, controls alternated with brain stimulation trials at 3-min intervals. From a PCPA-pretreated cat. $B$, The graph plots integrated responses of the same unit as in $A$ against temperature of heat stimulus, without $(\odot$, control) and during PVG stimulation $(O)$. Lines were calculated by linear regression analysis. PVG stimulation sites are shown in the inset (for abbreviations, see legend to Fig. $1 B$ ). $C$, Graph as in $B$, plotting mean responses of 11 units against temperature of heat stimulus without ( $Q$, control) and during PVG, medial preoptic, or basal forebrain stimulation $(\mathrm{O})$.

brain reticular formation in the cat (Parent and Steriade, 1981). It is also possible that neurons mediating descending inhibition release one or more inhibitory transmitter(s) in addition to $5-\mathrm{HT}$, such that depletion of 5-HT would weaken but not abolish inhibition.

Pathways for inhibition. Descending inhibition from the PVG may have been mediated via direct spinal projections originating in posterior (Kuypers and Maisky, 1975; Basbaum and Fields, 1979) or paraventricular (Hancock, 1976; Hosoya, 1980) hypothalamic nuclei, or indirectly via connections with the midbrain PAG (Conrad and Pfaff, 1976b; Grofova et al., 1978; Saper et al., 1979) and/or medullary NRM (Abols and Basbaum, 1981). Our results indicate that 5-HT may be involved in this inhibition, yet 5-HT-containing neuronal cell bodies were not found in the diencephalon, forebrain, or spinal cord in a recent extensive study (Steinbusch, 1981). The implication is that the PVG must be functionally linked with 5-HT-containing neurons located in the dorsal raphe nucleus in and ventral to the PAG, and/

or in the pontomedullary raphe nuclei including NRM (Steinbusch, 1981). Several observations suggest that the PAG may mediate descending inhibition from the PVG: (1) PVG and PAG stimulation produces parametrically similar inhibition of spinal neurons (Carstens et al., 1979; Carstens, 1982), and inhibition is blocked by methysergide and PCPA; (2) stimulation in the medial diencephalon predominantly excites PAG neurons (Sakuma and Pfaff, 1980); and (3) analgesia produced by medial diencephalic stimulation is blocked by PAG lesions, whereas analgesia produced by PAG stimulation is not blocked by medial diencephalic lesions (Rhodes, 1979). Descending inhibition from the PAG may, in turn, be mediated via activation of neurons in NRM (Fields and Anderson, 1978; Lovick et al., 1978) which project in the dorsolateral funiculi to terminate in the spinal dorsal horn (Basbaum et al., 1978). Double-label studies have shown that many raphe-spinal projection neurons also contain 5-HT (Bowker et al., 1981). The inhibitory spinal effect of NRM stimulation is abolished in PCPA-pretreated animals (Rivot et al., 1980), and raphe-spinal inhibition and analgesia resulting from PAG stimulation are blocked by dorsolateral funicular lesions (Basbaum et al., 1977; Fields et al., 1977; Willis et al., 1977). In summary, descending inhibition from the PVG might involve a serial PAG-NRM-spinal pathway.

5 -HT-containing neurons were recently reported in the PVG region of rats pretreated with pargyline and Ltryptophan (Frankfurt et al., 1981). Such neurons could conceivably mediate descending inhibition, but it is not known whether they give rise to descending projections.

Descending inhibition produced by stimulation of the medial basal forebrain could be mediated via a direct projection to the dorsal raphe/PAG (Aghajanian and Wang, 1977) or via connections with the medial preoptic area (Swanson and Cowan, 1979; Krayniak et al., 1980), which in turn connects with more posterior areas of the medial hypothalamus and midbrain (Conrad and Pfaff, 1976a; Sakai et al., 1977; Beitz, 1982). It was recently reported that medial septal stimulation excited some neurons in the PAG (DeNasi and Thomas, 1982). Alternatively, inhibition from the medial basal forebrain may involve a projection to the lateral hypothalamic area (Swanson and Cowan, 1979; Krayniak et al., 1980); stimulation of which also inhibits dorsal horn neurons (Carstens et al., 1983). The PAG and NRM receive projections from the lateral hypothalamic area (Abols and Basbaum, 1981).

One final possibility is that inhibition could be mediated via antidromic activation of neurons in NRM or the dorsal raphe nucleus from more anterior stimulation sites. Raphe neurons give rise to extensive ascending projections (Moore et al., 1978; Kohler et al., 1982); conceivably, some may give off both ascending and descending collaterals.

\section{References}

Abbot, F. V., and R. Melzack (1978) Analgesia produced by stimulation of limbic structures and its relation to epileptiform after-discharges. Exp. Neurol. 62: 720-734.

Abols, I. A., and A. I. Basbaum (1981) Afferent connections of the rostral medulla of the cat: A neural substrate for mid- 
brain-medullary interactions in the modulation of pain. $\mathrm{J}$. Comp. Neurol. 201: 285-297.

Aghajanian, G. K., and R. Y. Wang (1977) Habenular and other midbrain raphe afferents demonstrated by a modified retrograde tracing technique. Brain Res. 122: 229-242.

Akil, H., and J. C. Liebeskind (1975) Monoaminergic mechanisms of stimulation-produced analgesia. Brain Res. 94: 279 296.

Andy, O. J., and H. Stephan (1964) The Septum of the Cat, Charles C Thomas Publishers, Springfield, IL.

Basbaum, A. I., and H. L. Fields (1979) The origin of descending pathways in the dorsolateral funiculus of the spinal cord of the cat and rat: Further studies on the anatomy of pain modulation. J. Comp. Neurol. 187: 513-532.

Basbaum, A. I., N. J. E. Marley, J. O'Keefe, and C. H. Clanton (1977) Reversal of morphine and stimulus-produced analgesia by subtotal spinal cord lesions. Pain 3: 43-56.

Basbaum, A. I., C. H. Clanton, and H. L. Fields (1978) Three bulbospinal pathways from the rostral medulla of the cat: An autoradiographic study of pain modulating systems. J. Comp. Neurol. 178: 209-224.

Beck, P. W., H. O. Handwerker, and M. Zimmermann (1974) Nervous outflow from the cat's foot during noxious radiant heat stimulation. Brain Res 67: 373-386.

Beitz, A. J. (1982) The organization of afferent projections to the midbrain periaqueductal gray of the rat. Neuroscience 7 : 133-159.

Belcher, G., R. W. Ryall, and R. Schaffner (1978) The differential effects of 5-hydroxytryptamine, noradrenaline and raphe stimulation on nociceptive and non-nociceptive dorsal horn interneurones in the cat. Brain Res. 151: 307-321.

Black, P., S. N. Cianci, and R. S. Markowitz (1972) Alleviation of pain by hypothalamic stimulation in the monkey. Confin. Neurol. 34: 374-381.

Bleier, R. (1961) The Hypothalamus of the Cal, Johns Hopkins University Press, Baltimore.

Bowker, R. M., H. W. M. Steinbusch, and J. D. Coulter (1981) Serotonergic and peptidergic projections to the spinal cord demonstrated by a combined retrograde HRP histochemical and immunocytochemical staining method. Brain Res. 211: $412-417$.

Breglio, V., D. C. Anderson, and H. K. Merrill (1970) Alteration in footshock threshold by low-level septal brain stimulation. Physiol. Behav. 5: 715-7.

Carstens, E. (1982) Inhibition of spinal dorsal horn neuronal responses to noxious skin heating by medial hypothalamic stimulation in the cat. J. Neurophysiol. 48: 808-822.

Carstens, E., T. Yokota, and M. Zimmermann (1979) Inhibition of spinal neuronal responses to noxious skin heating by stimulation of mesencephalic periaqueductal gray in the cat. J. Neurophysiol. 42: 558-568.

Carstens, E., D. Klumpp, and M. Zimmermann (1980) Differential inhibitory effects of medial and lateral midbrain stimulation on spinal neuronal discharges to noxious skin heating in the cat. J. Neurophysiol. 43: 332-342.

Carstens, E., M. Fraunhoffer, and M. Zimmermann (1981) Serotonergic mediation of descending inhibition from midbrain periaqueductal gray, but not reticular formation, of spinal nociceptive transmission in the cat. Pain 10:149-167.

Carstens, E., J. D. MacKinnon, and M. J. Guinan (1982) Inhibition of spinal dorsal horn neuronal responses to noxious skin heating by medial preoptic and septal stimulation in the cat. J. Neurophysiol. 48: 981-991.

Carstens, E., M. Fraunhoffer, and S. N. Suberg (1983) Inhibition of spinal dorsal horn neuronal responses to noxious skin heating by lateral hypothalamic stimulation in the cat. J. Neurophysiol. 50: 192-204.

Clineschmidt, B. V., and E. G. Anderson (1970). The blockade of bulbospinal inhibition by 5 -hydroxytryptamine antagonists. Exp. Brain Res. 11: 175-186.

Conrad, L. C., and D. W. Pfaff (1976a) Efferents from medial basal forebrain and hypothalamus in the rat. I. An autoradiographic study of the medial preoptic area. J. Comp. Neurol. 169: 185-220.

Conrad, L. C. A., and D. W. Pfaff (1976b) Efferents from medial basal forebrain and hypothalamus in the rat. II. An autoradiographic study of the anterior hypothalamus. J. Comp. Neurol. 169: 221-262.

Coote, J. H., V. H. Macleod, and I. L. Martin (1978) Bulbospinal tryptaminergic neurones. Pflügers Arch. 377: 109-116.

DeNasi, P. C., and E. Thomas (1982). The effects of septal stimulation on spontaneous and tail-shock evoked neuronal activity in the brainstem of the rat. Brain Res. 249: 63-71.

Fields, H. L. and S. D. Anderson (1978) Evidence that raphespinal neurons mediate opiate and midbrain stimulationproduced analgesias. Pain 5: 333-349.

Fields, H. L., and A. I. Basbaum (1978) Brainstem control of spinal pain-transmission neurons. Annu. Rev. Physiol. 40: 217-248.

Fields, H. L., A. I. Basbaum, C. H. Clanton, and S. D. Anderson (1977) Nucleus raphe magnus inhibition of spinal cord dorsal horn neurons. Brain Res. 126: 441-453.

Frankfurt, M., J. M. Lauder, and E. C. Azmitia (1981) The immunocytochemical localization of serotonergic neurons in the rat hypothalamus. Neurosci. I ett. 24: 227-232.

Gol, A. (1967) Relief of pain by electrical stimulation of the septal area. J. Neurol. Sci. 5: 115-120.

Griersmith, B. T., and A. W. Duggan (1980) Prolonged depression of spinal transmission of nociceptive information by 5 HT administered in the substantia gelatinosa: Antagonism by methysergide. Brain Res. 187: 231-239.

Griersmith, B. T., A. W. Duggan, and R. A. North (1981) Methysergide and supraspinal inhibition of the spinal transmission of nociceptive information in the anesthetized cat. Brain Res. 204: 147-158.

Grofova, I., O. P. Ottersen, and E. Rinvik (1978) Mesencephalic and diencephalic afferents to the superior colliculus and periaqueductal gray substance demonstrated by retrograde axonal transport of horseradish peroxidase in the cat. Brain Res. 146: 205-220.

Guilbaud, G., J. L. Oliveras, G. Giesler, Jr., and J. M. Besson (1977) Effects induced by stimulation of the centralis inferior nucleus of the raphe on dorsal horn interneurons in cat's spinal cord. Brain Res. 126: 355-360.

Guinan, M. J., J. D. MacKinnon, and E. Carstens (1982) Serotonin involvement in descending inhibition of spinal nociceptive transmission by medial diencephalic and septal stimulation. Soc. Neurosci. Abstr. 8: 769.

Hancock, M. B. (1976) Cells of origin of hypothalamo-spinal projections in the rat. Neurosci. Lett. 3: 179-184.

Handwerker, H. O., A. Iggo, and M. Zimmermann (1975) Segmental and supraspinal actions on dorsal horn neurons responding to noxious and non-noxious skin stimuli. Pain 1: $147-165$.

Hayes, R. L., P. G. Newlon, J. A. Rosecrans, and D. J. Mayer (1977) Reduction of stimulation-analgesia by lysergic acid diethylamide, a depressor of serotonergic neural activity. Brain Res. 122: 367-372.

Headley, P. M., A. W. Duggan, and B. T. Griersmith (1978) Selective reduction by noradrenaline and 5-hydroxytryptamine of nociceptive responses of cat dorsal horn neurones. Brain Res. 145: 185-189.

Heath, R. G., and W. A. Mickle (1960) Evaluation of seven years' experience with depth electrode studies in human patients. In Electrical Studies on the Unanesthetized Brain, E. R. Ramey and D. S. O' Doherty, eds., pp. 214-247, Paul 
B. Hoeber, Inc., New York.

Hosobuchi, Y., J. E. Adams, and R. Linchitz (1977) Pain relief by electrical stimulation of the central gray matter in humans and its reversal by naloxone. Science 197: 183-186.

Hosoya, Y. (1980) The distribution of spinal projection neurons in the hypothalamus of the rat, studied with the HRP method. Exp. Brain Res. 40: 7987.

Keller, H. H. (1972) Depletion of cerebral monoamines by $p$ chlorophenylalanine in the cat. Experientia 28: 177-178.

Koe, K. B., and A. Weissman (1966) p-Chlorophenylalanine: A specific depletor of brain serotonin. J. Pharmacol. Exp. Ther. 154: 499-516.

Kohler, C., V. Chan-Palay, and H. Steinbusch (1982) The distribution of serotonin-containing fibers in the septal area: a combined immunohistochemical and fluorescent retrograde tracing study in the rat. J. Comp. Neurol. 209: 91-111.

Krayniak, P. F., S. Weiner, and A. Siegel (1980) An analysis of the efferent connections of the septal area in the cat. Brain Res. 189: 15-29.

Kuypers, H. G. J. M., and V. A. Maisky (1975) Retrograde axonal transport of horseradish peroxidase from spinal cord to hrain stem cell groups in the cat. Neurosci. Lett. 1: 9-14.

Lovick, T. A., D. C. West, and J. H. Wolstencroft (1978) Responses of raphe spinal and other bulbar raphe neurones to stimulation of the periaqueductal gray in the cat. Neurosci. Lett. 8: 45-49.

Mayer, D. J., and J. C. Liebeskind (1974) Pain reduction by focal electrical stimulation of the brain: An anatomical and behavioral analysis. Brain Res. 68: 73-93.

Mayer, D. J., and D. D. Price (1976) Central nervous system mechanisms of analgesia. Pain 2: 379-404.

Messing, R. B., and L. D. Lytle (1977) Serotonin-containing neurons: Their possible role in pain and analgesia. Pain 4: $1-21$.

Moore, R. Y., A. E. Halaris, and B. E. Jones (1978) Serolonin neurons of the midbrain; Ascending projections. J. Comp. Neurol. 180: 417-438.

Oleson, T. D., D. B. Kirkpatrick, and S. J. Goodman (1980) Elevation of pain threshold to tooth shock by brain stimulation in primates. Brain Res. 194: 79-95.

Oliveras, J. L., J. M. Besson, G. Guilbaud, and J. C. Liebeskind (1974) Behavioral and electrophysiological evidence of pain inhibition from midbrain stimulation in the cat. Exp. Brain Res. 20: 32-44.

Oliveras, J. L., F. Redjemi, G. Guilbaud, and J. M. Besson (1975) Analgesia induced by electrical stimulation of the inferior centralis nucleus of the raphe in the cat. Pain 1: 139 145.

Parent, A., and M. Steriade (1981) Afferents from the periaqueductal gray, medial hypothalamus and medial thalamus to the midbrain reticular core. Brain Res. Bull. 7: 411-418.

Price, D. D., and R. Dubner (1977) Neurons that subserve the sensory-discriminative aspects of pain. Pain 3: 307-338.

Proudfit, H. K., A. A. Larson, and E. G. Anderson (1980) The role of GABA and serotonin in the mediation of raphe-evoked spinal cord dorsal root potentials. Brain Res. 195: 149-165.

Randić, M., and H. H. Yu (1976) Effects of 5-hydroxytryptamine and bradykinin in cat dorsal horn neurones activated by noxious stimuli. Brain Res. 111: 197-203.

Rexed, B. (1952) The cytoarchitectonic organization of the spinal cord in the cat. J. Comp. Neurol. 96: 415-495.

Rhodes, D. L. (1979) Periventricular system lesions and stim- ulation-produced analgesia. Pain 7: 51-63.

Rivot, J. P., A. Chaouch, and J. M. Besson (1980) Nucleus raphe magnus modulation of response of rat dorsal horn neurons to unmyelinated fiber inputs: Partial involvement of serotonergic pathways. J. Neurophysiol. 44: 1039-1057.

Ruda, M. A., and S. Gobel (1980) Ultrastructural characterization of axonal endings in the substantia gelatinosa which take up $\left[{ }^{3} \mathrm{H}\right]$ serotonin. Brain Res. 184: 57-83.

Sakai, K., D. Salvert, M. Touret, and M. Jouvet (1977) Afferent connections to the nucleus raphe dorsalis in the cat as visualized by the horseradish peroxidase technique. Brain Res. 137: 11-35.

Sakuma, Y., and D. W. Pfaff (1980) Covergent effects of lordosis-relevant somatosensory and hypothalamic influences on central gray cells in the rat mesencephalon. Exp. Neurol. 70: 269-281.

Saper, C. B., L. W. Swanson, and W. M. Cowan (1979) Some efferent connections of the rostral hypothalamus in the squirrel monkey (Saimiri sciureus) and the cat. J. Comp. Neurol. 184: 205-242.

Satoh, M., A. Akaike, T. Nakazawa, and H. Takagi (1980) Evidence for involvement of separate mechanisms in the production of analgesia by electrical stimulation of the nucleus reticularis paragiganto-cellularis and nucleus raphe magnus in the rat. Brain Res. 194: 525-529.

Schmidek, H. H., D. Fohanno, F. R. Ervin, and W. H. Sweet (1971) Pain threshold alterations by brain stimulation in the monkey. J. Neurosurg. 35: 715-722.

Sinclair, J. G., and B. S. R. Sastry (1974) The blockade of bulbospinal inhibition by imipramine, desipramine and pargyline. Neuropharmacology 13: 643-650.

Snider, R. S., and W. J. Niemer (1961) A Sterentaxic Atlas of the Cat Brain, University of Chicago Press, Chicago.

Steinbusch, H. W. M. (1981) Distribution of serotonin-immunoreactivity in the central nervous system of the rat-Cell bodies and terminals. Neuroscience 6: 557-618.

Swanson, L. W., and W. M. Cowan (1979) The connections of the septal region in the rat. J. Comp. Neurol. 186: 621-656.

Willcockson, W. S., K. D. Gerhart, C. L. Cargill, and W. D. Willis (1982) Effect of serotonin and norepinephrine on raphe-spinal cells. Soc. Neurosci. Abstr. 8: 805.

Willis, W. D. (1982) Control of nociceptive transmission in the spinal cord. Prog. Sens. Physiol. Monograph 3, D. Ottoson, ed., Springer-Verlag, Berlin.

Willis, W. D., L. H. Haber, and R. F. Martin (1977) Inhibition of spinothalamic tract cells and interneurons by brain stem stimulation in the monkey. J. Neurophysiol. 40:968-981.

Yaksh, T. L., J. DuChateau, and T. A. Rudy (1976) Antagonism by methysergide and cinanserin of the antinociceptive action of morphone administered into the periaqueductal gray. Brain Res. 104: 367-372.

Yezierski, R. P., G. A. Kevetter, R. M. Bowker, K. N. Westlund, J. D. Coulter, and W. D. Willis (1981) Midbrain projections to the caudal brainstem: A double label study using HRP and serotonin (5-HT) immunohistochemistry. Anat. Rec. 199: $284 \mathrm{~A}$.

Yezierski, R. P., T. K. Wilcox, and W. D. Willis (1982) The effects of serotonin antagonists on the inhibition of primate spinothalamic tract cells produced by stimulation in nucleus raphe magnus or periaqueductal gray. J. Pharmacol. Exp. Ther. 220: 266-277. 